\title{
Existing Knowledge Assets and Disruptive Innovation: The Role of Knowledge Embeddedness and Specificity
}

\author{
Chunpei $\mathrm{Lin}^{1}$, Baixun $\mathrm{Li}^{2, *}$ and Yenchun $\mathrm{Jim} \mathrm{Wu}^{3,4}$ \\ 1 Business Management Research Center, School of Business Administration, Huaqiao University, \\ Quanzhou 362021, China; alchemist@hqu.edu.cn \\ 2 School of Business Administration, Guangdong University of Finance and Economics, \\ Guangzhou 510320, China \\ 3 Graduate Institute of Global Business and Strategy, National Taiwan Normal University, \\ Taipei 10645, Taiwan; wuyenchun@gmail.com \\ 4 School of Business Administration, Huaqiao University, Quanzhou 362021, China \\ * Correspondence: libaixun@gdufe.edu.cn
}

Received: 31 December 2017; Accepted: 26 January 2018; Published: 29 January 2018

\begin{abstract}
Disruptive innovation has created a significant impact on management practices and academia. This study investigated the impact of existing knowledge assets on disruptive innovation by analyzing the role of knowledge embeddedness and specificity. We conducted a hierarchical regression analysis by using survey data from 173 Chinese industrial firms to test the direct and indirect effects of knowledge embeddedness and specificity on disruptive innovation, which can be divided into outward-oriented and internal-oriented disruptive innovation. The results indicated that knowledge embeddedness not only played a positive role in knowledge specificity, but also had a positive effect on outward-oriented disruptive innovation. Furthermore, knowledge specificity exhibited opposite functions in outward-oriented and internal-oriented disruptive innovation. In addition, knowledge specificity mediated the relationship between knowledge embeddedness and outward-oriented (internal-oriented) disruptive innovation.
\end{abstract}

Keywords: knowledge assets; knowledge embeddedness; knowledge specificity; disruptive innovation

\section{Introduction}

Today, more companies have become increasingly aware of social and environmental pressures. The technological revolution characterized by intelligence, greenness, and ubiquity is booming and profoundly affecting the environment in which we work and live [1]. For example, Green information technology can be deployed to support a variety of sustainability initiatives such as to measure carbon footprints, reduce waste in business processes, lower resource consumption, and reduce greenhouse gas emissions [2]. Many scholars and consultants have argued that this technological revolution offers terrific opportunities for progressive organizations [3-5], as innovation is one of the primary means by which companies can achieve sustainable growth [6]. In particular, disruptive innovation is an important type of enterprise innovation and an important strategic tool for enterprises to realize technological revolution and achieve sustainable growth [7-9].

By referring to Adner [7], Christensen [8], and Govindarajan et al. [9], disruptive innovation can be viewed as a new product or service that introduces a different set of performance attributes relative to what already exists, and this set of attributes is initially attractive to an emerging customer segment. Case studies from Rafii and Kampas [10], Husig and Hipp [11], and Keller and Hüsig [12] found that disruptive innovation can be seen either as a threat or opportunity. When a disruptive 
product is introduced, but does not erode the existing market space, it will be perceived as an opportunity to expand into emerging markets. Thus, the disruptive product is given priority for resource allocation. Conversely, when the introduction of a disruptive product erodes the existing market, it can be considered as a potential threat and may force the enterprise to adjust its existing operating mode [13]. However, due to the impact of organizational inertia, the enterprise may resist this self-adjustment. Based on the above analysis, we divided disruptive innovation into outward-oriented disruptive innovation and internal-oriented disruptive innovation. Outward-oriented disruptive innovation refers to the process of introducing disruptive products into external markets to open up a new market or erode a rival's market share. Internal-oriented disruptive innovation refers to the process of introducing disruptive products into the existing product market and even completely replacing the existing market. The significant opportunities and challenges that disruptive innovation brings to business have made it one of the most influential innovation management theories over the past decade. Some companies have succeeded in initiating disruptive innovation. For example, Apple successfully ported the "iPod + iTunes" model to the mobile phone market and launched the "iPhone + App Store" mode. This led other mobile phone manufacturers such as Nokia, Blackberry, and HTC to the plight of development. According to Apple's successful practices on disruptive innovation, one natural question has arisen: how do existing knowledge assets (e.g., "iPod + iTunes" model) affect disruptive innovation?

According to the resource-based view, the essence of business behavior is to find a competitive advantage that is largely determined by the resources they own and control [14-16]. In particular, existing knowledge assets such as valuable and rare resources can play a significant role in disruptive innovation. Some papers have shown that existing knowledge assets are not conducive to disruptive innovation. For example, Christensen and Raynor [17] and Christensen [18], found that the various existing knowledge embedded in individuals, products, practices, etc., prompts the firm to favor sustaining innovation in the allocation of resources rather than disruptive innovations. Assink [19] also verified similar findings that previous and successful designs and product concepts could adversely affect their disruptive innovation. However, other papers have reported opposite results. For example, Lindsay and Hopkins [20], through a case study of Kimberly-Clarks, found that low-cost intellectual assets such as patents, trademarks, and publications, were a "two-pronged" strategic intellectual asset that could be used both to help businesses defend against external destructive threats and to eliminate internal barriers to disruptive innovation. Wan et al. [21], using a set of case studies of Chinese firms, developed propositions about how novel research \& development and production processes could foster disruptive innovation. To sum up, there is ambiguity over the role of existing knowledge assets in disruptive innovation. Recently, Fenech and Tellis [22] addressed the metrics, patterns, drivers, and predictive models of the dive and disruption of an existing product. Santoro et al. [23] investigated the relationship between a knowledge management system, open innovation, knowledge management capacity, and innovation capacity. Vecchiato [24] examined the relationship between managerial beliefs and the search processes for emerging markets, and found that in changing industries, the influence of prior history often increased the difficulty that decision-makers faced when seeking to respond to new events, and this difficulty then often resulted in organizational inertia and poor performance. These abovementioned studies tried to address the impact of existing knowledge assets on disruptive innovation, but the features of existing knowledge assets were rarely involved.

Some other scholars have introduced the feature of existing knowledge assets (such as observability, tacitness, and learnability), as antecedent or mediating variables into organizational behavior research to investigate their impact on knowledge transfer [25-28], organization structure [29], market performance [30], and innovation strategies [31]. In addition, other features of existing knowledge assets (e.g., knowledge embeddedness and knowledge specificity) have also attracted the attention of many researchers. In particular, knowledge embeddedness, as a recognized characteristic of knowledge, refers to the extent to which knowledge is embedded within an organization's individuals, dedicated assets, tools, organizational routines, and best practices as well as sub-networks $[25,32]$. 
Leszczyńska [33] argued that embedded knowledge and innovation influenced trajectory sequences in the long and discontinuous history of the cluster. Leszczyńska and Pruchnicki [34] investigated the impact of embedded knowledge on the efficiency of a localization choice made by a multinational corporation. Balland et al. [35] explained the formation of informal knowledge networks in clusters as an outcome of embeddedness, status, and proximity.

Meanwhile, asset specificity, as another important feature, refers to the notion that assets can only serve specific products and services, including site specificity, physical asset specificity, human asset specificity, dedicated asset specificity, and so on [36]. As an important type of intangible asset, knowledge also shows specificity. Moreover, knowledge specificity is not limited to specific products and services. There can also be specific businesses that consist of a series of products and services. Therefore, knowledge specificity can be referred to as the existing knowledge assets that can only serve the development of existing main business. Dibbern et al. [37] used data from 139 organizations on the sourcing of software development and maintenance services and found that production costs were generally lower in-house when knowledge specificity was high. Suh [38] investigated the role of excessive knowledge specificity in exhibiting the trusting ability of a firm. However, there have been few studies focusing on the role of knowledge embeddedness and knowledge specificity in affecting disruptive innovation.

To address these research gaps, based on the empirical analysis of data from 173 employees who engaged in product research and development, market monitoring, and product strategy formulation in Chinese manufacturing enterprises, we studied the impact of existing knowledge assets on disruptive innovation by taking into account the role of knowledge embeddedness and asset specificity. In summary, our paper makes two contributions. First, we divided disruptive innovations into outward-oriented disruptive innovation and internal-oriented disruptive innovation. This developed and supplemented Govindarajan and Kopalle's [9,39] scale for measuring disruptive innovation. Second, we added to the literature of disruptive innovation by investigating the impact of overall knowledge embeddedness and knowledge specificity on disruptive innovation, and provided a new perspective for the relationship between existing knowledge assets and disruptive innovation. The findings of this study revealed the role of knowledge embeddedness and knowledge specificity and provided practical information about understanding the impact of existing knowledge assets on disruptive innovation.

\section{Theoretical Background and Research Hypotheses}

According to Davenport and Prusak [40,41], knowledge is a flux mix of framed experiences, contextual information, values, and expert insight which provides a framework for evaluating and incorporating new experiences and information. Moreover, knowledge is dynamic since it is created in social interactions among individuals and organizations [42,43]. In particular, individual knowledge is the individual ability to draw distinctions within a collective domain of action under the appreciation of context or theory. Organizational knowledge is the capability developed by the members of an organization to draw distinctions in the process of carrying out their work [41]. According to the knowledge-based view, the overall intellectual capital can be defined as the sum of all the intangible and knowledge-related resources that an organization is able to use in its productive processes [44]. As an asset or capital, knowledge can play a significant role in disruptive innovation $[45,46]$. Therefore, we examined the impact of features of existing knowledge assets (e.g., knowledge embeddedness and knowledge specificity) on disruptive innovation.

\subsection{Knowledge Embeddedness and Knowledge Specificity}

According to Argote and Ingram [25] and Cummings and Teng [32], knowledge can be embedded in many different structural elements of an organization, such as in the people and their skills, the technical tools, and the routines and systems used by the organization, as well as in the networks formed between these elements. Moreover, Glisby and Holden [47] found that situational factors will 
constrain the process of knowledge creation and application. The higher the degree of knowledge embedded in culture, the more enterprises need to form a strong internal sharing network to communicate frequently and to ensure the effective flow of knowledge. In other words, knowledge specificity and application enhance the value of knowledge assets dedicated to a particular situation. However, if the external situation changes, such as the replacement of cultural context or external cooperation, the intrinsic value of the knowledge asset may be greatly reduced. Therefore, knowledge embeddedness will improve the situational applicability of knowledge assets and further strengthen knowledge specificity. On the other hand, Dayasindhu [48] and Jones et al. [49] pointed out that knowledge embeddedness would lead to the formation of various social mechanisms, such as restricted access (a limit on the number of members), collective sanctions (punishment meted out by constituents on erring partners), and reputation (the skills and reliability of the constituents), that coordinate and safeguard relations. The formation of these protection mechanisms restrains the conditions of occurrence and spatial extent of knowledge sharing, then enhances the extent to which these knowledge assets serve the firm's main businesses. As a result, knowledge embeddedness promotes the formation of protection mechanisms and further strengthens knowledge specificity. In summary, we proposed the following hypothesis:

Hypothesis 1. Knowledge embeddedness has a positive effect on knowledge specificity.

\subsection{Knowledge Embeddedness and Disruptive Innovation}

As mentioned above, disruptive innovation can be divided into outward-oriented disruptive innovation and internal-oriented disruptive innovation. We analyzed the role of knowledge embeddedness in outward-oriented disruptive innovation and internal-oriented disruptive innovation, respectively. As the extent of knowledge embeddedness increases, the knowledge can be mastered more deeply. This in-depth understanding enables companies to promptly transfer this knowledge into a usable form in response to changes in organizational needs and external market conditions to create more new products [50]. However, in the process of developing new products, knowledge embeddedness enables enterprises to search for solutions by using existing related knowledge, which presents obvious path-dependent characteristics. Such path-dependence will encourage enterprises to try hard to commercialize these high embedded knowledge assets in different industries, and then promote outward-oriented disruptive innovation. However, knowledge embeddedness also weakens the enterprise's self-willingness and motivation to replace the existing market, which is not conducive to the enterprise's internal-oriented disruptive innovation. Therefore, we proposed the following hypotheses:

Hypothesis 2a (H2a). Knowledge embeddedness has a positive effect on outward-oriented disruptive innovation.

Hypothesis $\mathbf{2 b} \mathbf{( H 2 b ) . ~ K n o w l e d g e ~ e m b e d d e d n e s s ~ h a s ~ a ~ n e g a t i v e ~ e f f e c t ~ o n ~ i n t e r n a l - o r i e n t e d ~ d i s r u p t i v e ~ i n n o v a t i o n . ~}$

\subsection{Knowledge Specificity and Disruptive Innovation}

Referring to Williamson's [51] definition of asset specificity, knowledge specificity is presented essentially as a lock-in effect. That is, once the knowledge assets dedicated to the development of the main businesses are identified, the relationship between the knowledge assets and main businesses will be continuously strengthened over time. Thus, the existing knowledge assets are locked [52]. If an enterprise tries to use these locked knowledge assets in other business areas, it will greatly discount its economic value. Therefore, the lock-in effect stipulates that companies must expand along the lines of their main businesses. In fact, this lock-in effect is a kind of path dependence and will have an impact on innovation activities. In other words, knowledge specificity can help enterprises continue to gain competitive advantages in the main business and guide enterprises in devoting more resources to carrying out innovation activities related to the main businesses. Moreover, these innovative activities 
are bound to promote the application of core technologies in different industries, thus promoting outward-oriented disruptive innovation [53-55]. However, as the extent of knowledge specificity is higher, it may lead to the rigidification of core competencies in the main business, and ignore the disruptive innovation opportunities that erode the market share of the main businesses [56]. Therefore, we proposed the following hypothesis:

Hypothesis 3a (H3a). Knowledge specificity has a positive effect on outward-oriented disruptive innovation.

Hypothesis $\mathbf{3 b} \mathbf{( H 3 b ) . ~ K n o w l e d g e ~ s p e c i f i c i t y ~ h a s ~ a ~ n e g a t i v e ~ e f f e c t ~ o n ~ i n t e r n a l - o r i e n t e d ~ d i s r u p t i v e ~ i n n o v a t i o n . ~}$

\subsection{The Mediating Role of Knowledge Specificity}

Existing knowledge assets are the foundation of enterprise innovation, and enterprise innovation activity is an important manifestation of the application of existing knowledge assets. The features of the existing knowledge assets determine the direction and scope for enterprises to carry out innovative activities by using the existing knowledge assets. Knowledge embeddedness can detract from the flexibility of existing knowledge assets and let the application of existing knowledge assets focus on a particular area, thus limiting the direction and scope of an enterprise's innovation activities [31]. Moreover, highly embedded knowledge assets are often those that have been successful in helping enterprises achieve sustained growth and have path-dependent characteristics. Thus, it is inclined to outward-oriented disruptive innovation rather than internal-oriented disruptive innovation in the allocation of resources. This preference is largely due to knowledge specificity, which encourages companies to make innovative investments in areas they are better at or more familiar with to minimize risks and costs. On the other hand, Hsu and Wang [57] as well as Mura et al. [58] also found that knowledge assets embedded in tools, individuals, and relational networks bound the value realization of knowledge into specific situations. This lock-in effect of knowledge assets not only reduces the risk of knowledge spillover, but also strengthens the knowledge specificity. In summary, we proposed the following hypotheses:

Hypothesis 4a (H4a). Knowledge specificity mediates the relationship between knowledge embeddedness and outward-oriented disruptive innovation.

Hypothesis $4 \mathbf{b}(\mathbf{H} 4 \mathbf{b})$. Knowledge specificity mediates the relationship between knowledge embeddedness and internal-oriented disruptive innovation.

Based on prior studies, this study proposed the conceptual model shown in Figure 1.

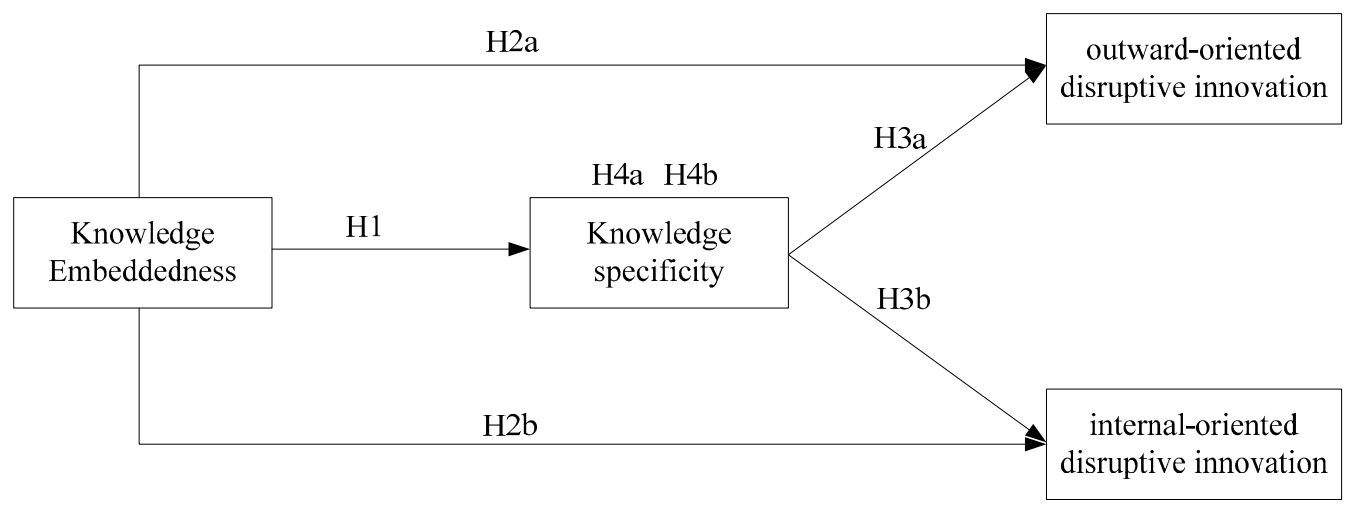

Figure 1. Conceptual model. 


\section{Methods}

\subsection{Participants and Procedure}

The participants were technical directors and senior presidents who engaged in product research and development, market monitoring, and product strategy formulation in Chinese manufacturing enterprises, and were familiar with product innovation activities. Two hundred and fifty questionnaires were sent, and the sample was reduced to 173 (69.2\%) after deleting the forms returned by those who declined to participate or who failed to answer all of the items. Descriptive statistical analysis of valid samples found that the proportion of males (53.8\%) was slightly higher than that of females $(46.2 \%)$; the proportion of middle managers and top managers was $67.6 \%$ and $28.9 \%$, respectively. As for the organizational characteristics of the surveyed enterprises, there were $126(72.9 \%)$ enterprises that had been established for more than 10-15 years, 114 (65.9\%) enterprises with 300 or more employees, and $142(82.1 \%)$ private enterprises. In addition, these enterprises were mainly located in the specialized and general equipment manufacturing industries $(12.7 \%)$, computer and telecommunications and other electronic equipment manufacturing industries (19.1\%), automobile manufacturing industry $(12.1 \%)$, chemical raw materials and chemical products manufacturing industry $(9.2 \%)$, and the electrical machinery and equipment manufacturing industry $(15.6 \%)$. Other manufacturing sectors amounted to less than $5 \%$ together.

In this study, we used three methods to collect samples. First, questionnaires were distributed on-site in local innovative training courses. These trained personnel mainly came from manufacturing enterprises in Quanzhou, Xiamen, Fuzhou, and other places in Fujian Province. Second, we commissioned a third-party platform (e.g., WenJuan Xing, the largest questionnaire distribution platform in China) to search the right sample companies and contact product development staff to complete the questionnaire. Third, we directly handed out questionnaires to related staff in qualified companies during our visits and project surveys.

\subsection{Variables and Measures}

\subsubsection{Knowledge Embeddedness}

To measure knowledge embeddedness, we modified the scales presented by Cummings [59] to fit the Chinese scenes, and designed four sample items including "It is difficult for a competitor to obtain the know-how of the company through field observation", "It is difficult for a competitor to obtain the know-how by studying production equipment", "It is difficult for a competitor to obtain the know-how by testing and using the product", and "It is difficult for a competitor to know how it works only by the company's activities, tasks, and procedures". The Cronbach's alpha for the scale was 0.806 .

\subsubsection{Knowledge Specificity}

Knowledge specificity intends to measure the extent to which the existing knowledge assets specifically service main businesses. By referring to Cable and DeRue [60], we developed the scale and five sample items including "The main businesses provide ample opportunities for the use of existing knowledge assets", "The existing knowledge assets have made significant contributions to the development of main businesses", "The existing knowledge assets have been widely used in the main businesses", "The existing knowledge assets provide value to the enterprise through the main businesses", and "The existing knowledge assets increase with the development of the main businesses". The Cronbach's alpha for the scale was 0.772 .

\subsubsection{Disruptive Innovation}

The scales of outward-oriented and internal-oriented disruptive innovation were referred from Christensen [8], Markides [61], Govindarajan and Kopalle [39], and Schmidt [62]. In particular, 
outward-oriented disruptive innovation included two sub-constructs of disruptive innovations: targeting new markets and targeting a competitor. The former had four items, including "Disruptive products target potential customers", "Disruptive products aim to predict future market needs", "Disruptive products aim to open up a new market", and "We often develop disruptive products for new markets". The Cronbach's alpha for the scale was 0.856 . The latter had three items, including "Disruptive products aim to substitute the competing products", "Disruptive products aim to reduce competitor's market share", and "Disruptive products aim to pose a market threat for competitors". The Cronbach's alpha for the scale was 0.711. As for internal-oriented disruptive innovation, there were also three measurement items including "Disruptive products decrease the market share of the existing products", "Disruptive products substitute existing products", and "Disruptive products decrease the sales of the existing products". The Cronbach's alpha for the scale was 0.772.

In addition, Chandy and Tellis [63] as well as Govindarajan and Kopalle [39] found that the strategic business unit (SBU) and the characteristics of the firm such as firm size and strategic autonomy also had an impact on the firm's innovation behaviors. In order to better observe the relationship between the main variables, we controlled the impact of establishment time, staff size, property rights, R\&D investment, and strategic autonomy. To avoid involving trade secrets, we measured the establishment time and staff size of the company by using the Likert four-point scale and measured the strategic autonomy by using the Likert seven-point scale, and investigated the potential impact of property rights by setting two dummy variables of state-owned enterprises and private enterprises. The measurement items of all of the constructs are presented in Appendix A, Table A1.

\section{Results and Discussion}

\subsection{Reliability and Validity Analysis}

The EFA (Exploratory Factor Analysis) method was used to test the structural validity of the scales. The results are shown in Table 1. In particular, the KMO (Kaiser-Meyer-Olkin) value of 19 sample items was 0.752, and the Chi-square value of Barlett's spherical test was 1378.183 (the degree of freedom was 171). Therefore, there were common factors in the correlation matrix and the factor analysis was suitable. Five factors were obtained from the factor analysis, which included disruptive innovation targeting new markets, disruptive innovation targeting competitors, internal-oriented disruptive innovation, knowledge embeddedness, and knowledge specificity. Meanwhile, the extent of common method variance (CMV) was examined using Harman's one-factor test. The results showed that five factors were extracted by principal component analysis, and explained the total variance of $66.037 \%$, while all factor loads after rotation were over 0.59 . In particular, one factor (i.e., disruptive innovation targeting new markets) explained a total variance of $23.53 \%$, which was less than half of the total variance. As a result, a single factor did not explain the vast majority of the amount of variation, and the common method variance was largely controlled.

Table 1. Exploratory factor analysis and Cronbach's alpha.

\begin{tabular}{|c|c|c|c|c|c|c|c|}
\hline \multirow{2}{*}{ Measurement Item } & \multicolumn{5}{|c|}{ Component } & \multirow{2}{*}{$\begin{array}{c}\text { Explained } \\
\text { Variance (\%) }\end{array}$} & \multirow{2}{*}{$\begin{array}{c}\text { Cronbach's } \\
\text { Alpha }\end{array}$} \\
\hline & 1 & 2 & 3 & 4 & 5 & & \\
\hline ODI 1 & 0.777 & 0.232 & 0.141 & 0.102 & 0.106 & \multirow{4}{*}{15.333} & \multirow{4}{*}{0.856} \\
\hline ODI 2 & 0.790 & 0.178 & -0.046 & 0.089 & 0.198 & & \\
\hline ODI 3 & 0.873 & 0.100 & 0.071 & -0.058 & 0.148 & & \\
\hline ODI 4 & 0.730 & -0.061 & 0.227 & 0.097 & 0.353 & & \\
\hline KS 1 & 0.124 & 0.672 & 0.120 & -0.194 & 0.051 & \multirow{5}{*}{14.162} & \multirow{5}{*}{0.772} \\
\hline KS 2 & -0.009 & 0.598 & 0.051 & -0.342 & 0.306 & & \\
\hline KS 3 & 0.137 & 0.767 & -0.020 & -0.166 & -0.022 & & \\
\hline KS 4 & -0.009 & 0.766 & 0.113 & 0.082 & 0.040 & & \\
\hline KS 5 & 0.160 & 0.653 & 0.054 & -0.089 & 0.059 & & \\
\hline
\end{tabular}


Table 1. Cont.

\begin{tabular}{|c|c|c|c|c|c|c|c|}
\hline \multirow{2}{*}{ Measurement Item } & \multicolumn{5}{|c|}{ Component } & \multirow{2}{*}{$\begin{array}{c}\text { Explained } \\
\text { Variance }(\%)\end{array}$} & \multirow{2}{*}{$\begin{array}{c}\text { Cronbach's } \\
\text { Alpha }\end{array}$} \\
\hline & 1 & 2 & 3 & 4 & 5 & & \\
\hline KE 1 & 0.078 & 0.182 & 0.717 & 0.181 & -0.020 & \multirow{4}{*}{13.823} & \multirow{4}{*}{0.806} \\
\hline KE 2 & 0.203 & 0.039 & 0.737 & -0.236 & -0.015 & & \\
\hline KE 3 & -0.012 & -0.002 & 0.869 & -0.006 & 0.044 & & \\
\hline KE4 & 0.051 & 0.081 & 0.820 & -0.021 & -0.003 & & \\
\hline IDI 1 & 0.203 & -0.168 & -0.158 & 0.546 & 0.385 & \multirow{3}{*}{11.737} & \multirow{3}{*}{0.772} \\
\hline IDI 2 & 0.096 & -0.171 & 0.034 & 0.882 & -0.008 & & \\
\hline IDI 3 & -0.003 & -0.167 & 0.007 & 0.885 & 0.041 & & \\
\hline ODI 5 & 0.267 & 0.135 & -0.012 & 0.039 & 0.704 & \multirow{3}{*}{10.928} & \multirow{3}{*}{0.711} \\
\hline ODI 6 & 0.116 & 0.185 & -0.015 & -0.046 & 0.857 & & \\
\hline ODI 7 & 0.384 & -0.053 & 0.063 & 0.222 & 0.636 & & \\
\hline \multicolumn{6}{|c|}{ Cumulative Explained variance (\%) } & \multicolumn{2}{|c|}{66.037} \\
\hline \multicolumn{6}{|c|}{ Cronbach's alpha of the total scale } & \multicolumn{2}{|r|}{0.782} \\
\hline
\end{tabular}

Note: Extraction Method: Principal Component Analysis; Rotation Method: Varimax with Kaiser Normalization. $\mathrm{N}=173 . \mathrm{KE}=$ knowledge embeddedness, $\mathrm{KS}=$ knowledge specificity, $\mathrm{ODI}=$ outward-oriented disruptive innovation, IDI = internal-oriented disruptive innovation.

\subsection{Confirmatory Factor Analyses}

To enhance the stability of the model fitting results by averaging the highest and the lowest factor loading, we grouped and packaged the measurement items of disruptive innovation targeting new markets and disruptive innovation targeting competitors, and took the average of the group scores as the index value of outward-oriented disruptive innovation. As a result, we obtained four measurement items. On this basis, we checked the discriminant validity by confirmatory factor analyses. The results are shown in Table 2. It can be seen from Table 2 that the $\chi^{2} / \mathrm{df}$ of the four-factor model was 1.86 , the goodness of fit index (GFI) and non-normed fir index (NNFI) were close to 0.9 , the comparative fit index (CFI) and incremental fit index (IFI) were greater than 0.9 , the adjusted goodness of fit index (AGFI) was greater than 0.5 , and the root mean square error of approximation (RMSEA) was less than 0.1. The overall goodness of fit was good. Moreover, when compared with the other three models, the four-factor model was the best fitting model. This indicated that the four factors involved in this study had good discriminant validity and represented four different concepts.

Table 2. Results of confirmatory factor analyses.

\begin{tabular}{|c|c|c|c|c|c|c|c|c|c|c|}
\hline Model & Factor & $x^{2}$ & df & $x^{2} / \mathrm{df}$ & GFI & CFI & NNFI & IFI & AGFI & RMSEA \\
\hline Model 1 & 4 Factor: KS; KE; ODI; IDI & 182.56 & 98 & 1.86 & 0.89 & 0.91 & 0.89 & 0.91 & 0.85 & 0.07 \\
\hline Model 2 & 3 Factor: KS + KE; ODI; IDI & 583.13 & 103 & 5.66 & 0.68 & 0.48 & 0.40 & 0.49 & 0.58 & 0.17 . \\
\hline Model 3 & 2 Factor: KS + KE; ODI+IDI & 379.43 & 101 & 3.76 & 0.79 & 0.70 & 0.64 & 0.71 & 0.71 & 0.13 \\
\hline Model 4 & 1 Factor: $\mathrm{KS}+\mathrm{KE}+\mathrm{ODI}+\mathrm{IDI}$ & 735.41 & 104 & 7.07 & 0.61 & 0.32 & 0.22 & 0.33 & .049 & .019 \\
\hline
\end{tabular}

Note: $\mathrm{N}=173 . \mathrm{KE}=$ knowledge embeddedness, $\mathrm{KS}=$ knowledge specificity, ODI = outward-oriented disruptive innovation, IDI = internal-oriented disruptive innovation, GFI = goodness of fit index, CFI = comparative fit index, NNFI = non-normed fit index, IFI $=$ incremental fit index, AGFI = adjusted goodness of fit index, RMSEA = root mean square error of approximation.

\subsection{Correlation Analysis}

The mean, standard deviation, and correlation coefficients of the variables in this study are shown in Table 3. As seen from Table 3, knowledge embeddedness had a significant positive correlation with knowledge specificity $(r=0.19, p<0.05)$. As for the correlation between knowledge embeddedness and disruptive innovation, knowledge embeddedness had a significant positive correlation with outward-oriented disruptive innovation $(r=0.18, p<0.05)$, and had a negative correlation with internal-oriented disruptive innovation, but did not reach the significant level. In addition, knowledge specificity presented positive correlations with outward-oriented disruptive 
innovation $(r=0.27, p<0.01)$, but revealed negative correlations with internal-oriented disruptive innovation $(r=-0.33, p<0.01)$. Moreover, we found that the correlation coefficient $(r=0.22, p<0.01)$ between outward-oriented disruptive innovation and internal-oriented disruptive innovation was relatively low. Therefore, these two types of disruptive innovation are independent. These results laid the foundation for the following regression analysis.

Table 3. Descriptive statistics and correlation analysis.

\begin{tabular}{|c|c|c|c|c|c|c|c|c|c|c|}
\hline Variables & $\mathbf{M}$ & SD & 1 & 2 & 3 & 4 & 5 & 6 & 7 & 8 \\
\hline 1. Age of Enterprise & 3.00 & 0.869 & 1 & & & & & & & \\
\hline 2. Size of Enterprise & 2.89 & 0.796 & $0.46^{* *}$ & 1 & & & & & & \\
\hline 3. Ownership of Enterprise & 0.18 & 0.385 & $0.23 * *$ & $0.16^{*}$ & 1 & & & & & \\
\hline 5. Knowledge Embeddedness & 4.76 & 0.947 & 0.07 & 0.19 * & -0.01 & $0.17^{*}$ & 1 & & & \\
\hline 6. Knowledge Specificity & 5.76 & 0.617 & 0.11 & 0.07 & -0.06 & $0.32 * *$ & 0.19 * & 1 & & \\
\hline $\begin{array}{l}\text { 7. Outward-Oriented } \\
\text { Disruptive Innovation }\end{array}$ & 5.12 & 0.913 & 0.03 & 0.04 & -0.03 & $0.23 * *$ & 0.18 * & $0.27^{* *}$ & 1 & \\
\hline
\end{tabular}

Note: $\mathrm{N}=173 .{ }^{*} p<0.05,{ }^{* *} p<0.01$.

\subsection{Hierarchical Regression Analysis and Discussion}

In this section, we conducted hierarchical regression analysis to test our hypotheses. As shown in Table 4, all models (i.e., from Model 1 to 10) were used to test the abovementioned hypotheses. In particular, Models 1 (M1), 3 (M3), and 7 (M7) were denoted the benchmark models with controlled variables and investigated the impact of the enterprise's age, size, property rights, and strategic autonomy. Model 2 (M2) was used to verify the impact of knowledge embeddedness on knowledge specificity. Models 4 (M4) and 5 (M5) were used to verify the impact of knowledge embeddedness and knowledge specificity on outward-oriented disruptive innovation. Models 8 (M8) and 9 (M9) were used to verify the impact of knowledge embeddedness and knowledge specificity on internal-oriented disruptive innovation. Model 6 (M6) was used to verify the mediation effect of knowledge specificity on the relationship between knowledge embeddedness and outward-oriented disruptive innovation. Model 10 (M10) was used to test the mediation effect of knowledge specificity on the relationship between knowledge embeddedness and internal-oriented disruptive innovation. We found that across all models, the variance inflation factor was less than 10, which indicated that there was no multi-collinearity in the model and our results were reliable.

Table 4. Results of hierarchical regression analysis.

\begin{tabular}{|c|c|c|c|c|c|c|c|c|c|c|}
\hline \multirow{2}{*}{ Variables } & \multicolumn{2}{|c|}{ KS } & \multicolumn{4}{|c|}{ ODI } & \multicolumn{4}{|c|}{ IDI } \\
\hline & M1 & M2 & M3 & M4 & M5 & M6 & M7 & M8 & M9 & M10 \\
\hline $\mathrm{AE}$ & 0.09 & 0.10 & 0.01 & 0.01 & -0.02 & -0.01 & 0.02 & 0.02 & 0.04 & 0.05 \\
\hline SE & -0.01 & -0.03 & 0.01 & -0.02 & 0.01 & -0.02 & $-0.20^{*}$ & $\begin{array}{c}-0.20 \\
*\end{array}$ & $-0.21 *$ & $-0.21^{* * *}$ \\
\hline $\mathrm{OE}$ & -0.07 & -0.07 & -0.02 & -0.02 & -0.01 & -0.01 & -0.10 & -0.10 & -0.12 & -0.12 \\
\hline SA & $0.31^{* * *}$ & $0.29 * * *$ & $0.22 * *$ & $0.20^{*}$ & $0.16^{*}$ & $0.14^{+}$ & -0.11 & -0.11 & -0.01 & -0.02 \\
\hline $\mathrm{KE}$ & & $0.14^{+}$ & & $0.15 *$ & & 0.12 & & -0.10 & & 0.04 \\
\hline KS & & & & & $0.22 * *$ & 0.20 * & & & $-0.32 * * *$ & $-0.33^{* * *}$ \\
\hline $\mathrm{R} 2$ & 0.11 & 0.13 & 0.05 & 0.07 & 0.10 & 0.11 & & & 0.17 & 0.17 \\
\hline F & $5.36^{* * *}$ & $5.1^{* * *}$ & $2.25^{+}$ & $2.61 *$ & $3.40 * *$ & $3.30 * *$ & 3.31 * & $2.63 *$ & $6.50^{* * *}$ & $5.51^{* * *}$ \\
\hline VIF & & & & & $1.039 \leqq$ & $/ \mathrm{IF} \leqq 1.3$ & & & & \\
\hline
\end{tabular}

Note: $\mathrm{N}=173 . \mathrm{AE}=$ age of enterprise, $\mathrm{SE}=$ size of enterprise, $\mathrm{OE}=$ ownership of enterprise, $\mathrm{SA}=$ strategic autonomy, KE = knowledge embeddedness, KS = knowledge specificity, ODI = outward-oriented disruptive innovation, IDI $=$ internal-oriented disruptive innovation. ${ }^{* * *}$ Significant at $p<0.001$, ${ }^{* *}$ significant at $p<0.01$, * significant at $p<0.05,{ }^{+}$significant at $p<0.1$. 


\subsubsection{The Role of Knowledge Embeddedness in Knowledge Specificity}

Comparing Model 1 with Model 2, knowledge embeddedness had a significant positive influence on knowledge specificity $(\beta=0.14, p<0.1)$. Therefore, Hypothesis 1 was supported. This result indicates that if the knowledge assets were embedded in many different structural elements of an organization, it was more likely for the knowledge assets to serve the firm's main business. The findings complemented the results of Cummings and Teng [33], Un and Asakawa [64], and Lin et al. [31], where on the one hand, knowledge embeddedness makes knowledge asset transfer more difficult. On the other hand, knowledge embeddedness will attract companies to pay attention to strengthening their knowledge specificity.

\subsubsection{The Role of Knowledge Embeddedness in Disruptive Innovation}

Comparing Model 3 with Model 4 (alternatively Model 7 with Model 8), we can see that knowledge embeddedness had a significant positive impact on the outward-oriented disruptive innovation $(\beta=0.15, p<0.05)$. In contrast, the knowledge embeddedness had a negative impact on the internal-oriented disruptive innovation. However, it did not reach a significant level. Therefore, Hypothesis 2a was supported and Hypothesis 2b was not supported. This result demonstrated that the enterprises would pay more attention to more highly embedded knowledge, and more likely carry out disruptive innovation induced by highly embedded knowledge in various industries. Moreover, our result supports Lindsay and Hopkins's [20] finding that enterprises could replicate existing success patterns to other industry areas by using highly embedded knowledge. However, the negative impact of knowledge embeddedness on internal-oriented disruptive innovation was not supported. This may be due to the fact that highly embedded knowledge can be related to the main businesses or not. For example, some novel ideas embedded in individuals may not be related to the current main businesses and can be ignored at present, even if it will play a significant role in future internal-oriented disruptive innovation [20]. Therefore, we should analyze the importance and contribution of existing knowledge assets to the development of main businesses when we investigate the impact of knowledge embeddedness on disruptive innovation.

\subsubsection{The Role of Knowledge Specificity in Disruptive Innovation}

Comparing Model 3 with Model 5 (alternatively Model 7 with Model 9), it was found that knowledge specificity had a significant positive effect on the outward-oriented disruptive innovation ( $\beta=0.22, p<0.01)$, and had a significant negative effect on the internal-oriented disruptive innovation ( $\beta=-0.32, p<0.001)$. Therefore, both Hypotheses $3 \mathrm{a}$ and $3 \mathrm{~b}$ were supported. This indicates that as the extent of knowledge specificity becomes higher, the enterprises will devote more resources to carrying out disruptive innovation activities associated with the main business and ignore those disruptive innovations that may conflict with the main businesses. Our results support the research of Christensen and Raynor [17] and Assink [19], which indicated that the impact of knowledge specificity on disruptive innovation is related to the nature of the markets. In other words, as the knowledge assets are dedicated to the enterprise's main businesses, it can actively encourage enterprises to develop disruptive products that target competitors' markets or new markets. However, the knowledge assets focusing on the main businesses are often closely related to existing products, and restrain internal-oriented disruptive innovation. Therefore, this result also provides an explanation for the relationship between knowledge embeddedness and internal-oriented disruptive innovation.

\subsubsection{The Mediating Role of Knowledge Specificity}

Referring to the procedure proposed by Baron and Kenny [65], we tested the mediating effect of knowledge specificity. Based on the above analysis, we found that the prerequisites of verifying the mediate variables could be satisfied. Then, we verified the mediating effect of knowledge specificity on the relationship between knowledge embeddedness and outward-oriented disruptive 
innovation. The results are shown in Table 4. Comparing Model 6 with Model 4, the coefficient of knowledge embeddedness decreased significantly $(\beta=0.15 \rightarrow 0.12)$ and did not reached a significant level. Therefore, the mediating effect could be verified and Hypothesis 4 a was supported. However, as knowledge embeddedness had no significant effect on the internal-oriented disruptive innovation, then the mediating effect of knowledge specificity on the relationship between knowledge embeddedness and internal-oriented disruptive innovation did not exist. Therefore, Hypothesis $4 \mathrm{~b}$ could not be supported. This result once again shows that knowledge specificity can play a significant role in disruptive innovation. It can act as a bridge to transfer the positive effect induced by knowledge embeddedness on outward-oriented disruptive innovation.

\section{Conclusions}

In this paper, we investigated the impact of existing knowledge assets on disruptive innovation by analyzing the role of knowledge embeddedness and specificity. Based on an empirical analysis of the data from 173 employees who engaged in product research and development, market monitoring, and product strategy formulation in Chinese manufacturing enterprises, we found that first, knowledge embeddedness not only played a positive role in knowledge specificity, but also had a positive effect on outward-oriented disruptive innovation. Second, knowledge specificity exhibited opposite functions on outward-oriented and internal-oriented disruptive innovation. In particular, knowledge specificity showed remarkable and direct positive effects on outward-oriented disruptive innovation, but notably had negative effects on internal-oriented disruptive innovation. This revealed that an enterprise with higher knowledge specificity could allocate more resources to the main businesses. These results provide a possible explanation for understanding the different viewpoints of Christensen [8], Lindsay and Hopkins [20], and Assink [19]. In addition, we also verified the mediating effect of knowledge specificity on the relationship between knowledge embeddedness and outward-oriented disruptive innovation. To sum up, with consideration of the features of knowledge assets, we expanded the research coverage on disruptive innovation and supplemented the findings of Christensen [8], Assink [19], and Wagner [66] regarding the relationship between knowledge assets and disruptive innovation. It can be concluded that knowledge embeddedness and knowledge specificity are two critical features of knowledge assets influencing disruptive innovation.

The research conclusion presents significant inspiration for knowledge asset management and innovation management. First, existing knowledge assets are the basis of innovation development, but there is not an apparently positive relationship between them. It is crucial to analyze the features of knowledge assets when we consider disruptive innovation. Second, with regard to knowledge asset management, enterprises should establish knowledge asset evaluation systems to dynamically track and evaluate knowledge embeddedness and knowledge specificity to then provide guidance for developing related disruptive innovation. Third, for innovation management, by making full use of the specialized knowledge assets of the main businesses, enterprises should promote the disruptive innovation of the existing knowledge assets in different industries.

However, this study had some limitations. First, this study adopted a convenient sample research approach with strong geographical features and industry limitations. In the future, we will expand the geographical scope of the samples. Second, embeddedness and specialization are only two of the features of knowledge assets. There also exist other important features which have had a significant impact on knowledge transfer and innovation. Subsequent studies can further explore the impact of other features on disruptive innovations. Third, the external environment is an important factor that affects enterprises in carrying out innovative activities [67]. Fourth, we should more comprehensively and holistically investigate the determinants of innovation and input more results to a mathematical model in future research. Therefore, further research should probe into the multi-layered factors and mechanisms of innovation management.

Acknowledgments: This study was supported financially by the Natural Science Foundation of China (71302163, 71401042, 71401151), Fund for Social Science Projects of Fujian Province in China (FJ2017B012), and the Humanities 
and Social Science Foundation Supported by the Ministry of Education in China (16YJC630160). Thanks are extended to Associate Professor Na Wang for language revision and suggestion on the paper's introduction.

Author Contributions: Chunpei Lin, Baixun Li, and Yenchun Jim Wu conceived and designed the experiments; Chunpei Lin performed the experiments; Chunpei Lin and Baixun Li analyzed the data; Yenchun Jim Wu contributed reagents/materials/analysis tools; Chunpei Lin and Baixun Li wrote the paper.

Conflicts of Interest: The authors declare no conflict of interest.

\section{Appendix A}

Table A1. Measures for key constructs.

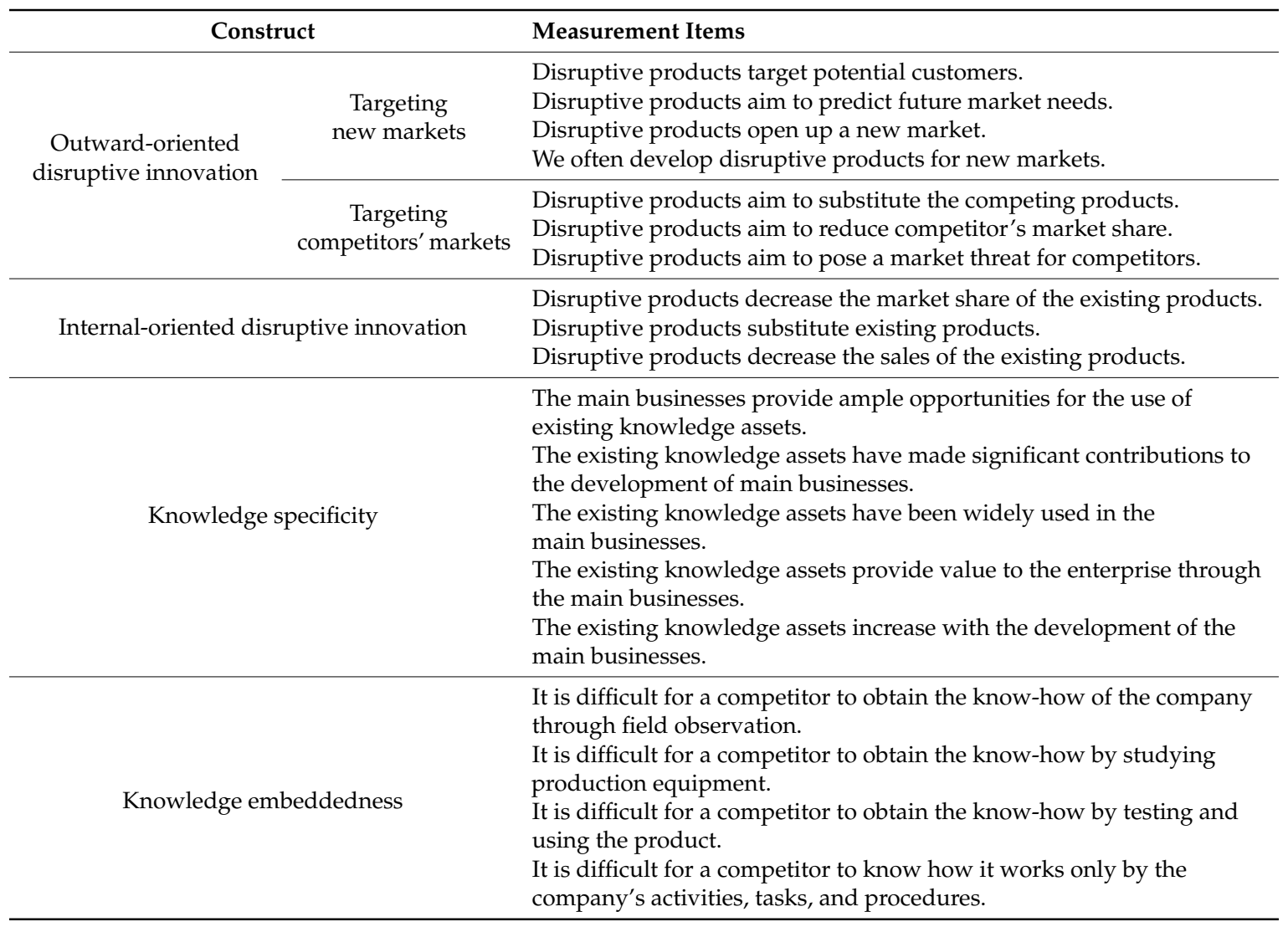

\section{References}

1. Carrasco, J.L.; Careaga, M.; Badilla-Quintana, M.G. The New Pyramid of Needs for the Digital Citizen: A Transition towards Smart Human Cities. Sustainability 2017, 12, 2258. [CrossRef]

2. Mohan, K.; Ramesh, B.; Cao, L.; Sarkar, B. Managing Disruptive and Sustaining Innovations in Green IT. IT Prof. 2012, 6, 22-29. [CrossRef]

3. Watson, R.T.; Boudreau, M.-C.; Li, S.; Levis, J. Telematics at UPS: En Route to Energy Informatics. MIS Q. Exec. 2010, 1, 1-11.

4. Wu, Y.C.J.; Pan, C.I.; Yuan, C.H. Attitudes towards the use of information and communication technology in management education. Behav. Inf. Technol. 2017, 3, 243-254. [CrossRef]

5. Abel, M.-H. Knowledge map-based web platform to facilitate organizational learning return of experiences. Comput. Hum. Behav. 2015, 1, 960-966. [CrossRef]

6. Hall, J.; Vredenburg, H. The challenges of innovating for sustainable development. MIT Sloan Manag. Rev. 2003, 1, 61-68.

7. Adner, R. When are technologies disruptive? A demand-based view of the emergence of competition. Strateg. Manag. J. 2002, 8, 667-688. [CrossRef] 
8. Christensen, C.M. The Innovator's Dilemma: When New Technologies Cause Great Firms to Fail; Harvard Business School Press: Boston, MA, USA, 1997.

9. Govindarajan, V.; Kopalle, P.K.; Danneels, E. The Effects of Mainstream and Emerging Customer Orientations on Radical and Disruptive Innovations. J. Prod. Innov. Manag. 2011, 28, 28,121-132. [CrossRef]

10. Rafii, F.; Kampas, P.J. How to identify your enemies before they destroy you? Harv. Bus. Rev. 2002, 80, 115-123. [PubMed]

11. Husig, S.; Hipp, C.; Dowling, M. Analyzing the disruptive potential: The case of wireless local area network and mobile communications network companies. R D Manag. 2005, 35, 17-35. [CrossRef]

12. Keller, A.; Hüsig, S. Ex-ante identification of disruptive innovations in the software industry applied to web applications: The case of Microsoft's vs. Google's office applications. Technol. Forecast. Soc. 2009, 76, 1044-1054. [CrossRef]

13. Gilbert, C.; Bower, J.L. Disruptive change. When trying harder is part of the problem. Harv. Bus. Rev. 2002, 80, 94-101. [PubMed]

14. Wernerfelt, B.A. A resource-based view of the firm. Strateg. Manag. J. 1984, 5, 171-180. [CrossRef]

15. Barney, J. Firm Resources and Sustained Competitive Advantage. J. Manag. 1991, 17, 90-120. [CrossRef]

16. Grant, R.M. Prospering in Dynamically-Competitive Environments: Organizational Capability as Knowledge Integration. Organ. Sci. 1996, 7, 375-387. [CrossRef]

17. Christensen, C.M.; Raynor, M.E. The Innovator's Solution: Creating and Sustaining Successful Growth; Harvard Business School Press: Boston, MA, USA, 2003.

18. Christensen, C.M. The Ongoing Process of Building a Theory of Disruption. J. Prod. Innov. Manag. 2006, 23, 39-55. [CrossRef]

19. Assink, M. Inhibitors of disruptive innovation capability: A conceptual model. Eur. J. Innov. Manag. 2006, 9, 215-233. [CrossRef]

20. Lindsay, J.; Hopkins, M. From experience: Disruptive Innovation and the Need for Disruptive Intellectual Asset Strategy. J. Prod. Innov. Manag. 2010, 27, 283-290. [CrossRef]

21. Wan, F.; Williamson, P.J.; Yin, E. Antecedents and implications of disruptive innovation: Evidence from China. Technovation 2015, 39, 94-104. [CrossRef]

22. Fenech, J.P.; Tellis, G.J. The Dive and Disruption of Successful Current Products: Measures, Global Patterns, and Predictive Model. J. Prod. Innov. Manag. 2016, 33, 53-68. [CrossRef]

23. Santoro, G.; Vrontis, D.; Thrassou, A.; Dezi, L. The Internet of Things: Building a knowledge management system for open innovation and knowledge management capacity. Technol. Forecast. 2017, in press. [CrossRef]

24. Vecchiato, R. Disruptive innovation, managerial cognition, and technology competition outcomes. Technol. Forecast. 2016, 116, 116-128. [CrossRef]

25. Argote, L.; Ingram, P. Knowledge Transfer: A Basis for Competitive Advantage in Firms. Organ. Behav. Hum. Decis. Process. 2000, 82, 150-169. [CrossRef]

26. Mcevily, B.; Argote, L.; Reagans, R. Managing Knowledge in Organizations: An Integrative Framework and Review of Emerging Themes. Manag. Sci. 2003, 49, 571-582.

27. Mciver, D.; Lepisto, D.A. Effects of knowledge management on unit performance: Examining the moderating role of tacitness and learnability. J. Knowl. Manag. 2017, 21, 796-816. [CrossRef]

28. Mostafa, R.; Klepper, S. Industrial Development through Tacit Knowledge Seeding: Evidence from the Bangladesh Garment Industry. Manag. Sci. 2017, in press. [CrossRef]

29. Birkinshaw, J.; Nobel, R.; Ridderstråle, J. Knowledge as a contingency variable: Do the characteristics of knowledge predict organization structure? Organ. Sci. 2002, 13, 274-289. [CrossRef]

30. Chong, W.K.; Bian, D.; Zhang, N. E-marketing services and e-marketing performance: The roles of innovation, knowledge complexity and environmental turbulence in influencing the relationship. J. Mark. Manag. 2016, 32, 149-178. [CrossRef]

31. Lin, H.E.; McDonough, E.F.; Yang, J.; Wang, C.Y. Aligning Knowledge Assets for Exploitation, Exploration, and Ambidexterity: A Study of Companies in High-Tech Parks in China. J. Prod. Innov. Manag. 2017, 34, 122-140. [CrossRef]

32. Cummings, J.L.; Teng, B.S. Transferring R\&D knowledge: The key factors affecting knowledge transfer success. J. Eng. Technol. Manag. 2003, 20, 39-68.

33. Leszczyńska, D. Historical trajectory and knowledge embeddedness: A case study in the French perfume cluster. Manag. Organ. Hist. 2013, 8, 290-305. 
34. Leszczyńska, D.; Pruchnicki, E. The evolution of knowledge transfer and the location of a multinational corporation: Theory and mathematical model. Multinatl. Bus. Rev. 2015, 23, 111-129. [CrossRef]

35. Balland, P.A.; Belsomartínez, J.A.; Morrison, A. The Dynamics of Technical and Business Knowledge Networks in Industrial Clusters: Embeddedness, Status, or Proximity? Econ. Geogr. 2016, 92, 35-60. [CrossRef]

36. Joskow, P.L. Asset Specificity and the Structure of Vertical Relationships: Empirical Evidence. J. Law Econ. Organ. 1988, 4, 95-117.

37. Dibbern, J.; Chin, W.W.; Kude, T. The Sourcing of Software Services: Knowledge Specificity and the Role of Trust. Data Base Adv. Inf. Syst. 2016, 47, 36-57. [CrossRef]

38. Suh, T. Exhibited trust and excessive knowledge specificity: A competitive altruism hypothesis. Ind. Mark. Manag. 2016, 62, 51-60. [CrossRef]

39. Govindarajan, V.; Kopalle, P.K. The usefulness of measuring disruptiveness of innovations ex post in making ex ante predictions. J. Prod. Innov. Manag. 2006, 23, 12-18. [CrossRef]

40. Davenport, T.H.; Prusak, L. Working Knowledge; Harvard University Press: Cambridge, MA, USA, 1998.

41. Tsoukas, H.; Vladimirou, E. What is organizational knowledge? J. Manag. Stud. 2001, 7, 973-993. [CrossRef]

42. Nonaka, L.; Takeuchi, H.; Umemoto, K. A theory of organizational knowledge creation. Int. J. Technol. Manag. 1996, 11, 833-845.

43. Hassan, S.-U.; Haddawy, P. Measuring International Knowledge Flows and Scholarly Impact of Scientific Research. Scientometrics 2013, 1, 163-179. [CrossRef]

44. Kianto, A.; Ritala, P.; Spender, J.C.; Vanhala, M. The interaction of intellectual capital assets and knowledge management practices in organizational value creation. J. Intellect. Cap. 2014, 3, 362-375. [CrossRef]

45. Scaringella, L. Knowledge, knowledge dynamics, and innovation: Exploration of the internationalization of a multinational corporation. Eur. J. Innov. Manag. 2016, 3, 337-361. [CrossRef]

46. Kang, M.; Lee, M.J. Absorptive capacity, knowledge sharing, and innovative behaviour of R\&D employees. Technol. Anal. Strateg. 2017, 29, 219-232.

47. Glisby, M.; Holden, N. Contextual constraints in knowledge management theory: The cultural embeddedness of Nonaka's knowledge-creating company. Knowl. Process Manag. 2003, 10, 29-36. [CrossRef]

48. Dayasindhu, N. Embeddedness, knowledge transfer, industry clusters and global competitiveness: A case study of the Indian software industry. Technovation 2002, 22, 551-560. [CrossRef]

49. Jones, C.; Hesterly, W.S.; Borgatti, S.P. A General Theory of Network Governance: Exchange Conditions and Social Mechanisms. Acad. Manag. Rev. 1997, 22, 911-945.

50. Nonaka, I. Toward Middle-Up-Down Management: Accelerating Information Creation. MIT Sloan Manag. Rev. 1988, 29, 9-18.

51. Wlliamson, O.E. The Economic Institutions of Capitalism; The Free Press: New York, NY, USA, 1985.

52. Fitzroy, F.R.; Mueller, D.C. Cooperation and Conflict in Contractual Organization. Q. Rev. Econ. Bus. 1984, $24,23-49$.

53. Allarakhia, M.; Walsh, S. Managing knowledge assets under conditions of radical change: The case of the pharmaceutical industry. Technovation 2011, 31, 105-117. [CrossRef]

54. Di Guardo, M.C.; Harrigan, K.R. Shaping the path to inventive activity: The role of past experience in R\&D alliances. J. Technol. Transf. 2016, 41, 1-20.

55. Zahra, S.; George, G. Absorptive capacity: A review, reconceptualization, and extension. Acad. Manag. Rev. 2002, 27, 185-203.

56. Wu, F.S.; Haak, R. Innovation mechanisms and knowledge communities for corporate central R\&D. Creat. Innov. Manag. 2013, 22, 37-52.

57. Hsu, L.C.; Wang, C.H. Clarifying the effect of intellectual capital on performance: The mediating role of dynamic capability. Br. J. Manag. 2012, 23, 179-205. [CrossRef]

58. Mura, M.; Radaelli, G.; Spiller, N.; Lettieri, E.; Longo, M. The effect of social capital on exploration and exploitation. J. Intellect. Cap. 2014, 15, 430-450. [CrossRef]

59. Cummings, J.L. Knowledge Transfer across RED Units: An Empirical Investigation of the Factors Affecting Successful Knowledge Transfer across Intra- and Inter-Organizational Units; UMI: Honk Kong, China, 2002; pp. 62-65.

60. Cable, D.M.; DeRue, D.S. The convergent and discriminant validity of subjective fit perceptions. J. Appl. Psychol. 2002, 87, 875-884. [CrossRef] [PubMed] 
61. Markides, C. Disruptive innovation: In need of better theory. J. Prod. Innov. Manag. 2006, 23, 19-25. [CrossRef]

62. Schmidt, G.M.; Druehl, C.T. When is a disruptive innovation disruptive? J. Prod. Innov. Manag. 2008, 25, 347-369. [CrossRef]

63. Chandy, R.K.; Tellis, G.J. Organizing for radical product innovation: The overlooked role of willingness to cannibalize. J. Mark. Res. 1998, 35, 474-487. [CrossRef]

64. Un, C.A.; Asakawa, K. Types of R\&D collaborations and process innovation: The benefit of collaborating upstream in the knowledge chain. J. Prod. Innov. Manag. 2015, 32, 138-153.

65. Baron, R.M.; Kenny, D.A. The moderator mediator variable distinction in social psychological research. J. Personal. Soc. Psychol. 1986, 51, 1173-1182. [CrossRef]

66. Wang, Y.; Vanhaverbeke, W.; Roijakkers, N. Exploring the impact of open innovation on national systems of innovation-A theoretical analysis. Technol. Forecast. Soc. 2012, 79, 419-428. [CrossRef]

67. Bouali, S.; Buscarino, A.; Fortuna, L.; Frasca, M.; Gambuzza, L.V. Emulating complex business cycles by using an electronic analogue. Nonlinear Anal. Real World Appl. 2012, 13, 2459-2465. [CrossRef]

(C) 2018 by the authors. Licensee MDPI, Basel, Switzerland. This article is an open access article distributed under the terms and conditions of the Creative Commons Attribution (CC BY) license (http://creativecommons.org/licenses/by/4.0/). 